Abstracta Iranicacta Iranica

Revue bibliographique pour le domaine irano-aryen

Volume 37-38-39 | 2018

Comptes rendus des publications de 2014-2016

\title{
Éloïse Brac de la Perrière, Monique Buresi (dir.). Le coran de Gwalior. Polysémie d'un manuscrit à peintures
}

\section{Sandra Aube}

\section{OpenEdition}

1 Journals

\section{Édition électronique}

URL : http://journals.openedition.org/abstractairanica/46570

DOI : 10.4000/abstractairanica.46570

ISBN : 1961-960X

ISSN : 1961-960X

Éditeur :

CNRS (UMR 7528 Mondes iraniens et indiens), Éditions de l'IFRI

Référence électronique

Sandra Aube, «Éloïse Brac de la Perrière, Monique Buresi (dir.). Le coran de Gwalior. Polysémie d'un manuscrit à peintures », Abstracta Iranica [En ligne], Volume 37-38-39 | 2018, document 4, mis en ligne le 30 décembre 2018, consulté le 02 octobre 2020. URL : http://journals.openedition.org/ abstractairanica/46570 ; DOI : https://doi.org/10.4000/abstractairanica.46570

Ce document a été généré automatiquement le 2 octobre 2020.

Tous droits réservés 


\title{
Éloïse Brac de la Perrière, Monique Buresi (dir.). Le coran de Gwalior. Polysémie d'un manuscrit à peintures
}

\author{
Sandra Aube
}

\section{RÉFÉRENCE}

Éloïse Brac de la Perrière, Monique Buresi (dir.). Le coran de Gwalior. Polysémie d'un manuscrit à peintures. Paris : Éditions de Boccard, 2016, 215p., nombreuses ill. couleur, ISBN : 978-2-7018-0443-9

1 La production des manuscrits à peintures dans l'Inde des Sultanats reste très méconnue jusqu'au XVI ${ }^{e}$ siècle. Le coran de Gwalior, conservé dans la collection Aga Khan (inv. AKM00281), fut copié dans la forteresse de Gwalior en 801/1399: il constitue le plus ancien manuscrit à peintures indien, à caractères arabes, daté avec certitude.

2 Ce coran, richement enluminé, est suivi d'un livre de divination (fāl-nāme). Le style varié des enluminures du coran de Gwalior le met en relation avec les productions iraniennes et proche-orientales du XIV ${ }^{e}$ siècle, tandis que son écriture bihari l'inscrit dans des traditions calligraphiques indiennes plus tardives. Outre ces problématiques liées à la codicologie et à l'histoire de l'art, le coran de Gwalior questionne par ailleurs l'œuvre coranique elle-même et ses usages.

Ce manuscrit exceptionnel fut l'objet, quatre années durant, d'un groupe de recherche dirigé par Éloïse Brac de la Perrière, spécialiste des arts du livre dans l'Inde islamique (cf. le cr dans Abstracta Iranica de L'art du livre dans l'Inde des sultanats, Paris, 2008). L'étude du coran de Gwalior s'est caractérisée par une approche pluridisciplinaire, assortie d'un dialogue fécond - cher à É. Brac de la Perrière - entre jeunes chercheurs et chercheurs confirmés.

4 Le volume collectif, que dirigent É. Brac de la Perrière et M. Buresi, réunit neuf articles (en anglais et en français) qui, à travers des approches très complémentaires, 
proposent une étude originale du Coran du Gwalior. Après une introduction d'É. Brac de la Perrière, le volume s'organise en trois parties :

5 - La première partie ( «Le coran de Gwalior ») propose une analyse minutieuse du manuscrit à travers trois articles portant sur les enluminures (Frantz Chaigne et Mathilde Cruvelier, "The ornamentation of the Gwalior Qur' an, between diachronic legacies and geographic confluences », p. 17-56), les pigments (Nourane Ben Azzouna et Patricia Roger-Puyo, «The Gwalior Qur'an: Archaeology of the manuscript and of its decoration: A preliminary study», p. 57-84), les gloses marginales et le fäl-nāme (Sabrina Alilouche et Ghazaleh Esmailpour Qouchani, «Les gloses marginales et le fälnāma du coran de Gwalior, témoignages des usages multiples du coran dans l'Inde des sultanats », p. 85-110).

6 - La seconde partie («Contextes») offre différents éclairages contextuels. Ainsi, Johanna Blayac étudie la présence musulmane à Gwalior avant le XVI siècle ("Contextualizing the Gwalior Qur'an: Notes on Muslim Military, Commercial and Mystical Routes in Gwalior and India before the $16^{\text {th }}$ century », p. 113-125). Nalini Balbir présente des codex indiens non-musulmans et établit notamment l'impact des livres jaïns sur le coran de Gwalior («Kalpasūtras et Corans: Réflexions sur l'écriture et la peinture de manuscrits jaina du Gujarat aux XIV ${ }^{e}$-XVI ${ }^{e}$ siècle», p. 127-138). Enfin, Asma Hilali présente les usages coraniques et les questions autour de la transmission des textes religieux ("Qur' an manuscripts as documentary sources », p. 139-150).

7 - La troisième partie ("Les manuscrits indo-persans et le monde islamique ») décrypte enfin le coran de Gwalior au travers de réseaux transrégionaux, offrant ainsi des perspectives contextuelles plus larges: Finbarr Barry Flood, «Eclecticism and Regionalism: The Gwalior Qur'an and the Ghurid Legacy to Post-Mongol Art " (p. 153-169), Yves Porter, « Lotus flowers and leaves, from China and Iran to the Indian Sultanates », p. 171-189), Simon Rettig, "A 'Timurid-like Response' to the Qur' an of Gwalior? Manuscript W563 at the Walters Art Museum, Baltimore » (p. 191-205).

\section{AUTEURS}

\section{SANDRA AUBE}

CNRS, Mondes iranien et indien, Paris 